\title{
SLURRY EROSIVE WEAR BEHAVIOR OF AA 6063/TIC PARTICLES IN SITU COMPOSITES
}

\author{
G. NAVEEN KUMAR ${ }^{1}$, V. MAHIDHAR REDDY ${ }^{2}$, M. SUNIL KUMAR ${ }^{3}$, \\ K. HEMACHANDRA REDDY ${ }^{4} \&$ Y. V. MOHANA REDDY ${ }^{5}$ \\ ${ }^{1}$ Associate Professor, Department of Mechanical Engineering, Institute of \\ Aeronautical Engineering, Dundigal, Hyderabad, Telangana, India \\ ${ }^{2,3}$ Assistant Professor, Department of Mechanical Engineering, Institute of \\ Aeronautical Engineering, Dundigal, Hyderabad, Telangana, India \\ ${ }^{4}$ Professor, Department of Mechanical Engineering, Jawaharlal Nehru Technological University \\ Anantapur, Anantapur, Andhra Pradesh, India \\ ${ }^{5}$ Professor, Department of Mechanical Engineering, G Pulla Reddy Engineering College, \\ Nandyal Road, Kurnool, Andhra Pradesh, India
}

\begin{abstract}
The In-situ composite of metal matrix AA6063-xTiC ( $x=0$ wt. \%, 3wt. \%, 6 wt. \%, 9 wt. \%) were mixed with particulates of Tic, were synthesized by the reaction of $\mathrm{K}_{2} \mathrm{TiF}_{6}$ and graphite with aluminum melt at $1000^{\circ} \mathrm{C}$. These composites were heat treated differently to form various sets like solution zed and solution zed-aged, where they were compared with as-cast composites for erosive wear performance by testing pot type slurry-erosive wear device, respectively. This study showed an increase in wear resistance for slurry erosion upon solution zed-aged heat treatment and with a rise of Tic particulates.
\end{abstract}

KEYWORDS: Metal Matrix, Wear and Slurry Erosion

Received: May 05, 2017; Accepted: May 25, 2017; Published: Jun 05, 2017; Paper Id.: IJMPERDJUN201724

\section{INTRODUCTION}

The class of innovative engineering materials of metal matrix composites (MMCs) is with a vast variety of wear, structural and thermal managerial applications. The metal-matrix composites can provide high-temperature working limits than their base metal corresponding element, and it can be tailored to give stiffness, thermal conductivity, enhanced strength, abrasion resistance, dimensional stability or creep resistance [1, 2].MMCs has been focused by record of the commercial work on aluminum as the metal matrix such as ventral fins, cylinder liners, helicopter blades and lower drag brace landing gears in modern fighter planes[3].The light weight and useful mechanical properties combination has ended aluminum alloys very popular; aluminum also makes these properties well-matched for use as a metal matrix. Though, aluminum itself shows deprived tribological properties [4]. Therefore, the importance in the study is the tribological behavior of aluminum based materials is becoming increasing. By continuous exposure to environment, these materials get degraded. Due to the continuous exposure to such environment, the body erosion in automotive applications wear of these materials plays a major role [5].

Aluminum melting point is more than enough to gratify many tender requirements, still little enough to reduce composite processing reasonably suitable. $\mathrm{B}_{4} \mathrm{C}, \mathrm{TiB}_{2}, \mathrm{Al}_{2} \mathrm{O}_{3}$, Sic, Tic, WC, and graphite variety of reinforcing 
agent which accommodates by the aluminum are regularly used as reinforcements. The matrix increases the stiffness and strength by incorporation of the reinforcement [6,7], increases the hardness of the composite with addition of hard ceramic particles, which improves the resistance of the matrix to reduce and penetrate subsequent removal of material by other third-body particles and wear debris found in the environment [8]. In particulate-reinforced metal matrix composites, Titanium carbide (Tic) was commonly used as reinforcement due to its relatively high thermal, high hardness, thermal stability, wear resistance, electrical conductivities and good wet ability.

To fabricate composite materials, various synthesizing techniques were used InTic reinforcement, such as in-situ melt reaction route and powder metallurgy route. Though, it has been observed that problem of contamination at matrixreinforcement interfaces the powder metallurgy route [9-11], to synthesize Tic reinforced in aluminum matrix, the in-situ approach is much economical and suitable. Through in-situ approach method of chemical reaction, many of the researchers have synthesized Tic particulates to form a very fine thermodynamically stable ceramic phase using Al-Ti-C system [1216]. In aluminum alloy the Tic particulates synthesis the chemical reaction of graphite powders and $\mathrm{K}_{2} \mathrm{TiF}_{6}$. The reaction temperature that played a critical role in synthesis of Tic from Al- $\mathrm{K}_{2} \mathrm{TiF}_{6}-\mathrm{C}$ system has been observed. SHS process (Selfpropagating High-temperature Synthesis) has been involved by synthesis of Tic particulates in aluminum matrix. In SHS process various parameters such as stochiometry of the reactants, pellet size, particle size and green density have been studied [17].

By different routes, many researchers investigated the erosion wear behavior of Al based composites [18-20]. Erosive wear resistance of the composites rises with the quantity of reinforcement that has been stated. For solid particles entrained in a fluid impinge on surface that occurs, erosion wear is major degradation mechanism for structural materials, which occurs [21-22].In the present investigation, no reports were formed in literature on this aspirant in-site composite material and hence an attempt towards slurry erosion wears. Further, study has been done on erosion wear influence of the heat treatment on Al-Si-Mg alloys. Thus, the increase in solution zing temperature and aging duration with maximum hardness for 6 hours aging duration it has been proved increasing of the hardness. Thus, Al-Si-Mg alloys exhibited improved wear resistance upon heat treatment [23].

In the present work, AA 6063 metal matrix composite has been synthesized through in-situ casting route with reinforcement up to 9 wt. \% of Tic. The synthesis of Ticwasperformed through impulsive reaction between graphite powders and $\mathrm{K}_{2} \mathrm{TiF}_{6}$ in aluminum alloy melts. The slurry wear of the composites for different conditions have been studied, with the pot type slurry erosion tester.

\section{EXPERIMENTAL DETAILS}

\section{Casting and Heat treatment}

To develop the Tic formation and its even distribution in AA 6063, matrix alkaline salt $\left(\mathrm{K}_{2} \mathrm{TiF}_{6}\right)$ and graphite powder were used. In Table 1, the insignificant chemical composition of AA 6063 alloy has been provided. By changing the mass of the above-mentioned chemicals added in the aluminum alloy melt in the fraction of Tic particulates has been varied. The chemical mass to be added in the melt, it has been calculated as per the stochiometric ratio to procedure composites $\mathrm{C}_{0}$ (AA 6063-0 wt.\% Tic), $\mathrm{C}_{1}$ (AA 6063-3 wt.\% Tic), $\mathrm{C}_{2}$ (AA 6063-6 wt.\% Tic) and $\mathrm{C}_{3}$ (AA 6063-9 wt.\% Tic).As shown in Table 2, the weights of chemicals added in different composites. 
Table 1:The Nominal Chemical Compositon of AA 6063 Alloy

\begin{tabular}{|c|c|c|c|c|c|c|c|c|c|}
\hline Element & $\mathbf{S i}$ & $\mathbf{F e}$ & $\mathbf{C u}$ & $\mathbf{M n}$ & $\mathbf{M g}$ & $\mathbf{Z n}$ & $\mathbf{T i}$ & $\mathbf{C r}$ & $\mathbf{A l}$ \\
\hline Weight percentage & $0.2-0.6$ & 0.35 & $0.1 \mathrm{max}$ & $0.1 \mathrm{max}$ & $0.45-0.9$ & $0.1 \mathrm{max}$ & $0.1 \mathrm{max}$ & $0.1 \mathrm{max}$ & Balance \\
\hline
\end{tabular}

Table 2: The Amounts of Chemicals Added for Various Composites

\begin{tabular}{|l|c|c|c|c|}
\hline & $\begin{array}{c}\text { C }_{0} \text { AA6063- } \\
\text { 0wt.\% Tic }\end{array}$ & $\begin{array}{c}\text { C }_{1} \text { AA6063- } \\
\text { 3wt.\% Tic }\end{array}$ & $\begin{array}{c}\text { C }_{2} \text { AA6063- } \\
\text { 6wt.\% Tic }\end{array}$ & $\begin{array}{c}\text { C }_{3} \text { AA6063- } \\
\text { 9wt.\% Tic }\end{array}$ \\
\hline K $_{\mathbf{2}}$ TiF in gm & 0 & 130 & 250 & 380 \\
\hline Graphite in gm & 0 & 6.25 & 12.50 & 18.75 \\
\hline
\end{tabular}

The chemicals $\mathrm{K}_{2} \mathrm{TiF}_{6}$ and graphite powder were prudently weighed as calculated earlier, and mixed thoroughlyto prepare the above-mentioned composites. Then, the AA6063 carefully weighed and added in a silica crucible, and it was kept inside the furnace. Thus, in the AA6063 alloy the prepared mixture of the chemicals was added and melt was preserved at the temperature of $1000^{\circ} \mathrm{C}$ for 30 minutes inside the furnace for in-situ growth of TiC particulates. To synthesize the Tic particulates from $\mathrm{K}_{2} \mathrm{TiF}_{6}$ and graphite powders important one is to maintain temperature ranges between $900^{\circ} \mathrm{C}$ to $1100{ }^{\circ} \mathrm{C}$. A vital exothermic reaction started soon after the accumulation of chemicals into the AA 6063 alloy melt. Then after the 10 minutes of time interval the mixture was stirred in the crucible. Finally, preheated to the temperature at $300{ }^{\circ} \mathrm{C}$ the molten mixture was carefully poured in a cast iron mould.

The cast blocks were laid open to two dissimilar heat treatments after casting the composites, viz., AA 6063 - tic $(\mathrm{x}=0,3,6$ and $9 \mathrm{wt} . \%)$. Thus, based on their condition the sets of composites were prepared. In as-cast condition, the first set of composites was remained and not heat treated. For one hour, the second set of composites was solution zed at $530{ }^{\circ} \mathrm{C}$ and then quenched in water. The composites of third set weresolution zed as second set,and also followed by aging at $175^{\circ} \mathrm{C}$ for 8 hours. The characterization of the prepared composites has been done using optical microscope. Using the Hitachi S-3000 H scanning electron microscope, the images of Tic particulates in the composites have been taken. Also, for the composites of $\mathrm{C}_{0}, \mathrm{C}_{1}, \mathrm{C}_{2}$ and $\mathrm{C}_{3}$ the micro hardness of different conditions has been measured by using Wick 3212 Vickers hardness tester. Using the D/MAX ULTIMA III XRD machine supplied by Rigaku Corporation, Japan, with CuKa radiation $\left(1.54056 \mathrm{a}^{\circ}\right)$ the X-ray diffraction analyses (XRD) for the composites with varying Tic content in as-cast condition were conducted.

\section{Slurry-Erosion Test}

Erosion wear tests were carried out using a pot type slurry-erosive wear apparatus supplied by Friction and Wear Tech., Chennai, India. An abrasive particle slurry comprising silica sand (white, with a mesh size 30/80) with 33\% sand concentration and remaining water was used. The composite specimens were rotated in the slurry with a speed of 500 rpm for 8 hours' test duration. The mass loss was measured after each hour using an electronic weighing balance with an accuracy of $0.0001 \mathrm{gms}$, and then, the specimens were kept again in same position for erosive wear tests. The amount of wear was quantified by measuring the volume loss. The wear rate was given as: volume loss $/$ distance traversed $\left(\mathrm{mm}^{3} / \mathrm{km}\right)$. The surface morphologies of the worn-out surface of the composites were studied by scanning electron microscope (SEM). 


\section{RESULTS AND DISCUSSION}

\section{Characterization of the Composites}

\section{Micro Hardness Analysis}

Table 3: Hardness Values of the in Situ Composite as Different Conditions

\begin{tabular}{|c|c|c|c|}
\hline $\begin{array}{c}\text { Weight Percentage of } \\
\text { Tic }\end{array}$ & $\begin{array}{c}\text { As Cast Condition } \\
\mathbf{H v}_{\mathbf{0 . 5}}\end{array}$ & $\begin{array}{c}\text { Solution Zed } \\
\text { Condition } \mathbf{H v}_{\mathbf{0 . 5}}\end{array}$ & $\begin{array}{c}\text { Solution Zed-Aged } \\
\text { Condition }_{\mathbf{H v}}\end{array}$ \\
\hline 0 & 56 & 72 & 76 \\
\hline 3 & 63 & 88 & 89 \\
\hline 6 & 80 & 103 & 108 \\
\hline 9 & 92 & 118 & 123 \\
\hline
\end{tabular}

The results obtained from micro hardness testing using Vickers hardness tester (Wick 3212) with an indentation load of $0.5 \mathrm{Kg}$ and dwell time of $15 \mathrm{sec}$. are shown in Table 3. The results reveal that by increasing the weight percent of Tic, the hardness values increase due to an increase in volume fraction of hard phase. The in-situ composites with solution zed-aged condition exhibited an improved hardness compared with the composites either in solution zedor in as-cast condition. The improved hardness values of the composites in solution zed-aged condition can be attributed to the formation of fine $\mathrm{Mg}_{2} \mathrm{Si}$ precipitates from AA 6063 matrix. After comparing with the composites in as-cast condition, the composite in solution zed condition exhibited a better hardness value. The reason may be associated with homogenization and uniform distribution of Tic particles after the solution zing heat treatment.

\section{Scanning Electron Microscopy}

SEM images taken from a Hitachi S 3000-H microscope is shown in Figure 1. In the high magnification images,

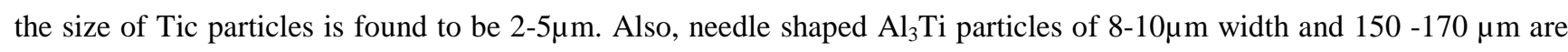
observed.

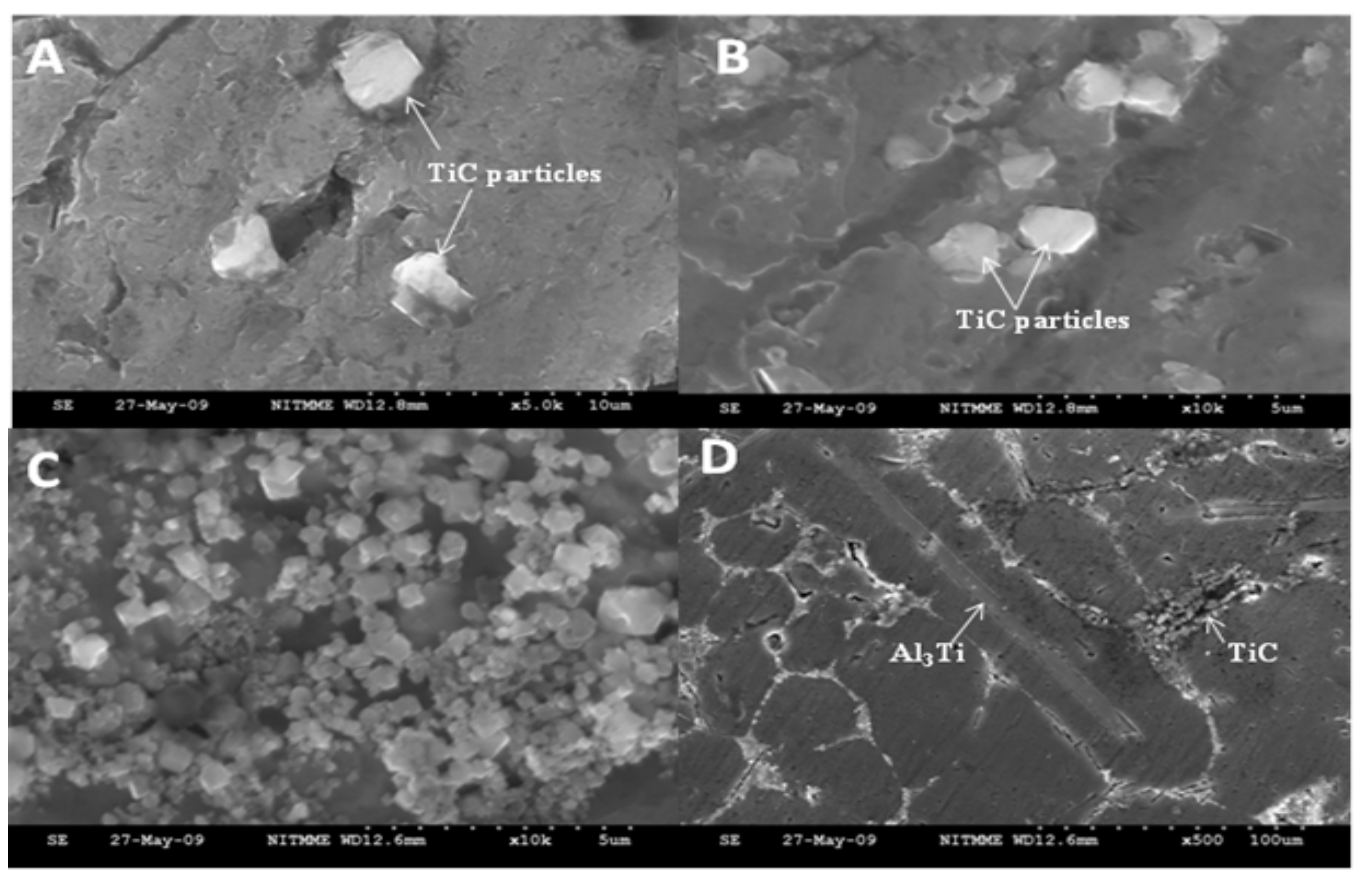

Figure 1: SEM Micrographs of AA 6063/Tic Composite with as-Cast Condition A) $\mathrm{C}_{1}$, B) $\mathrm{C}_{2}$, C) $\mathrm{C}_{3}$ and D) $\mathrm{C}_{3}$ Showing $\mathrm{Al}_{3} \mathrm{Ti}$ and Tic particles 


\section{X-Ray Diffraction Analysis}

X-ray Diffraction (XRD) patterns of the matrix specimen and of the specimens reinforced with different percentages by weight of Tic are shown in Fig. 2. It shows the X-ray diffraction (XRD) patterns obtained from the crosssection of cast composites viz., $\mathrm{C}_{0}, \mathrm{C}_{1}, \mathrm{C}_{2}$ and $\mathrm{C}_{3}$. All the peaks are identified as arising from three phases namely, Albased phase, Tic and $\mathrm{Al}_{3}$ Ti from JCPDS files (file no. 892837, 893828 and 650428) respectively.

Also, through a relative comparison of the XRD patterns of composites $\mathrm{C}_{1}, \mathrm{C}_{2}$ and $\mathrm{C}_{3}$, it can be seen that with an increase of weight fraction of Tic particulates the corresponding peaks of Tic and $\mathrm{Al}_{3} \mathrm{Ti}$ show an increase in relative intensity. From the XRD peak profile analysis, the area under the peak was measured and the relative fractions of Tic were determined in the case of composites $\mathrm{C}_{1}, \mathrm{C}_{2}$ and $\mathrm{C}_{3}$. The volume fractions of the corresponding composites were calculated as $2.85 \%, 4.20 \%$ and $7.25 \%$. These reduced fractions are attributed to the melting losses, as against the targeted values.

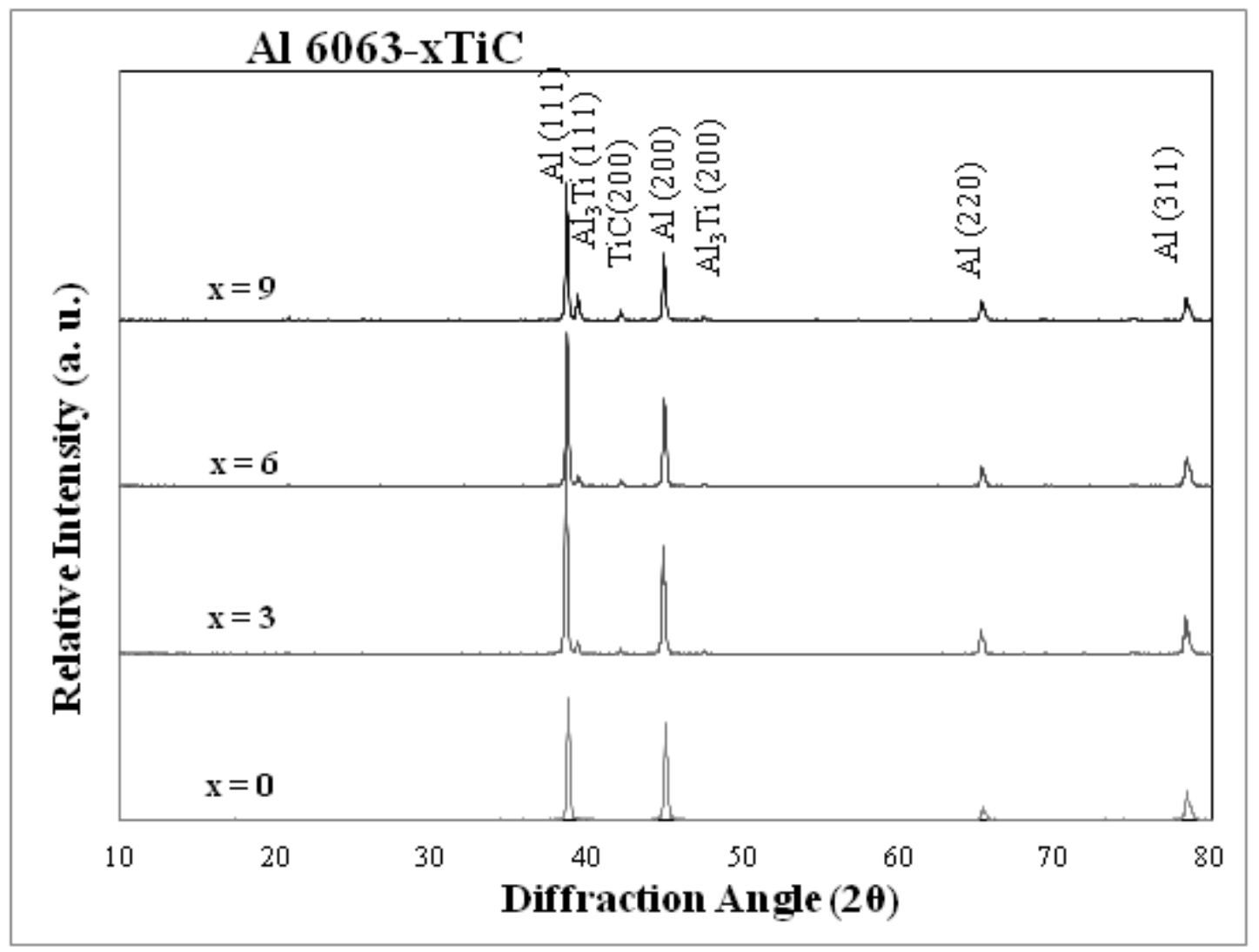

Figure.2: XRDResults For the AA 6063/TicComposites

\section{Slurry Erosive Wear}

The slurry erosive wear rate of the composites was computed from mass loss measurements. The variation of cumulative mass loss of the composites $\mathrm{C}_{0}, \mathrm{C}_{1}, \mathrm{C}_{2}$ and $\mathrm{C}_{3}$ for different heat treated conditionswith interval of an hour is shown in Figure 3. 

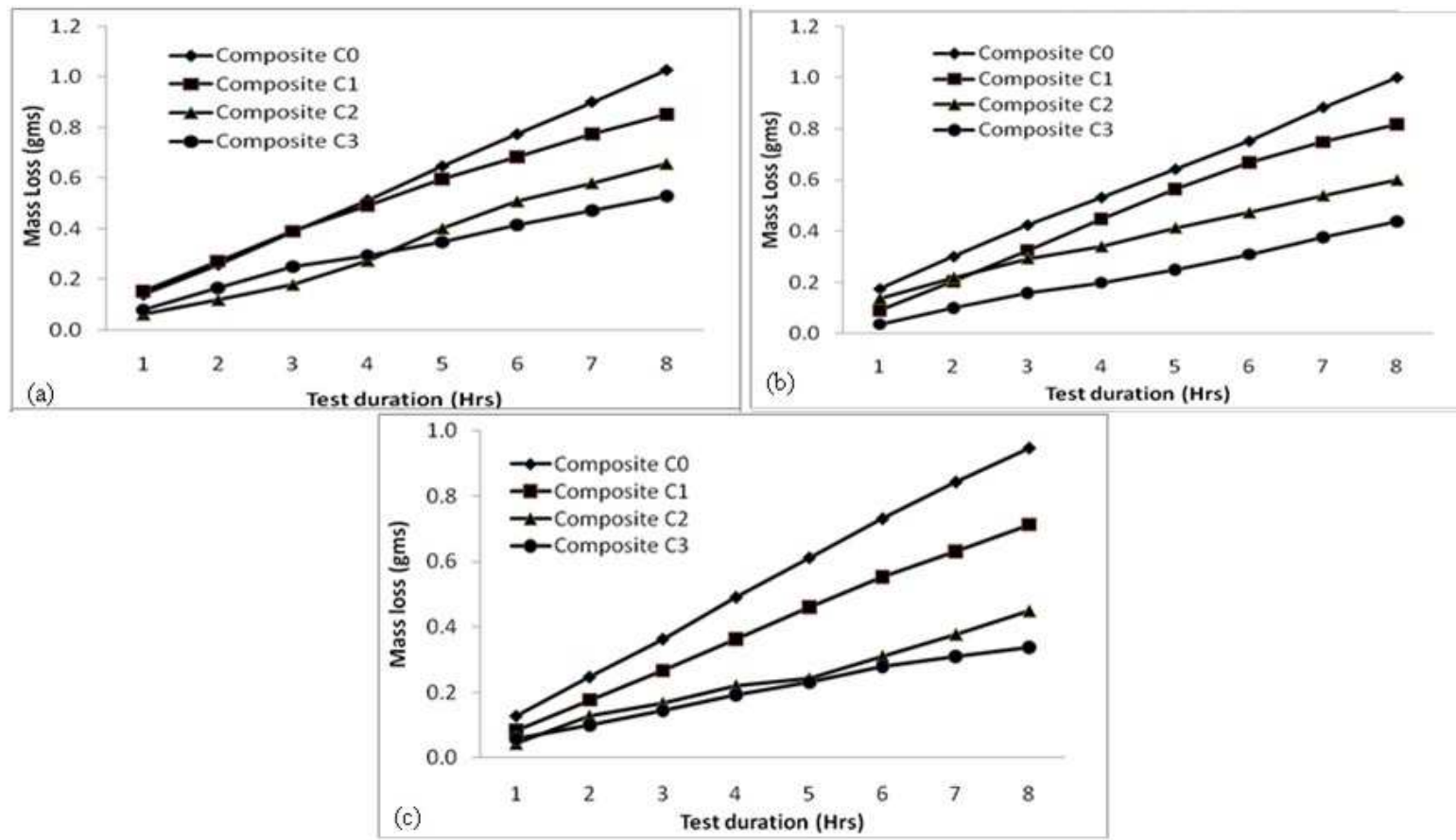

Figure 3: Cumulative Mass Loss of the Composites with (a) As-Cast, (b) Solution Zed and (c) Solution Zed-Aged Conditions for Test Duration of 8 hrsC $\mathrm{h}_{0}$-AA 6063/0\% Tic, $\mathrm{C}_{1}$-AA 6063/3\% Tic, $\mathrm{C}_{2}$-AA 6063/6\% Tic and $\mathrm{C}_{3}$-AA 6063/9\% Tic

A linear plot was observed for unreinforced alloy $C_{0}$ for all conditions. It indicates a uniform wear with time, whereas, in the case of composites $\mathrm{C}_{1}, \mathrm{C}_{2}$ and $\mathrm{C}_{3}$ nonlinear plots are observed. It may be attributed to the inhomogeneity in the presence of Tic particles in the composites $\mathrm{C}_{1}, \mathrm{C}_{2}$ and $\mathrm{C}_{3}$.

With increase in weight fraction of Tic particles, the mass loss of the composites decreased. This can be explained by the more resistance offered due to Tic particles causing less indentation and scratches in aluminum matrix. The composite $C_{1}$ showed a linear relationship of mass loss against time up to 4-5 hours of test duration. Thereafter, marginal decrease in mass loss is observed by the slope of the curve for composite $\mathrm{C}_{1}$. The composite $_{3}$ offered maximum resistance to erosion wear among all composites. The total mass loss observed for composites $\mathrm{C}_{0}, \mathrm{C}_{1}, \mathrm{C}_{2}$ and $\mathrm{C}_{3}$ with as-cast condition after 8 hours of test duration was 1.026, $0.850,0.656$ and 0.528 grams,respectively. The total mass loss observed for composites $\mathrm{C}_{0}, \mathrm{C}_{1}, \mathrm{C}_{2}$ and $\mathrm{C}_{3}$ with solution zed condition after 8 hours of test duration was $1.001,0.817,0.599$ and 0.437 grams respectively. The total mass loss observed for composites $\mathrm{C}_{0}, \mathrm{C}_{1}, \mathrm{C}_{2}$ and $\mathrm{C}_{3}$ with solution zed-aged condition after 8 hours of test duration was $0.947,0.713,0.449$ and 0.338 grams respectively. It is clear from the results that the composites with solution zed-aged condition showed lesser mass loss than composites with solution zed and as-cast conditions. This may be attributed to increase in hardness of the matrix due to precipitation hardening. Fig. 4 shows the variation of erosive wear rate after 8 hours of test duration for all composites with different conditions. Wear rate is found to decrease with increase in weight fraction of Tic particles. The decrease in slope from composite $\mathrm{C}_{2}$ indicates that the change in wear from composite $C_{1}$ to $C_{2}$ is more than the change in wear from composite $C_{2}$ to $C_{3}$. 


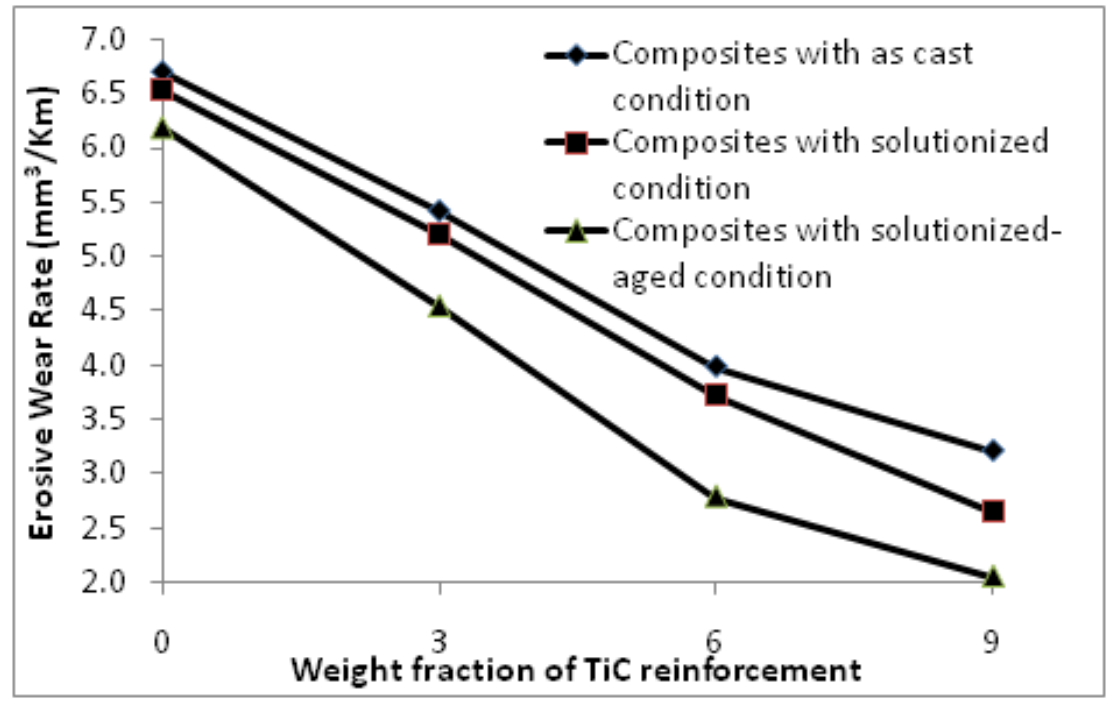

Figure4: Effect If TicReinforcement on Erosive Wear Rate

The erosive surfaces were studied using SEM with the aim of understanding the mechanism of material removal. Figure 5 shows the SEM micrographs of worn surfaces of composites with solutionized-aged condition. The SEM micrograph (Fig.12a) of unreinforced alloy shows deep and wide plowing and cutting grooves.

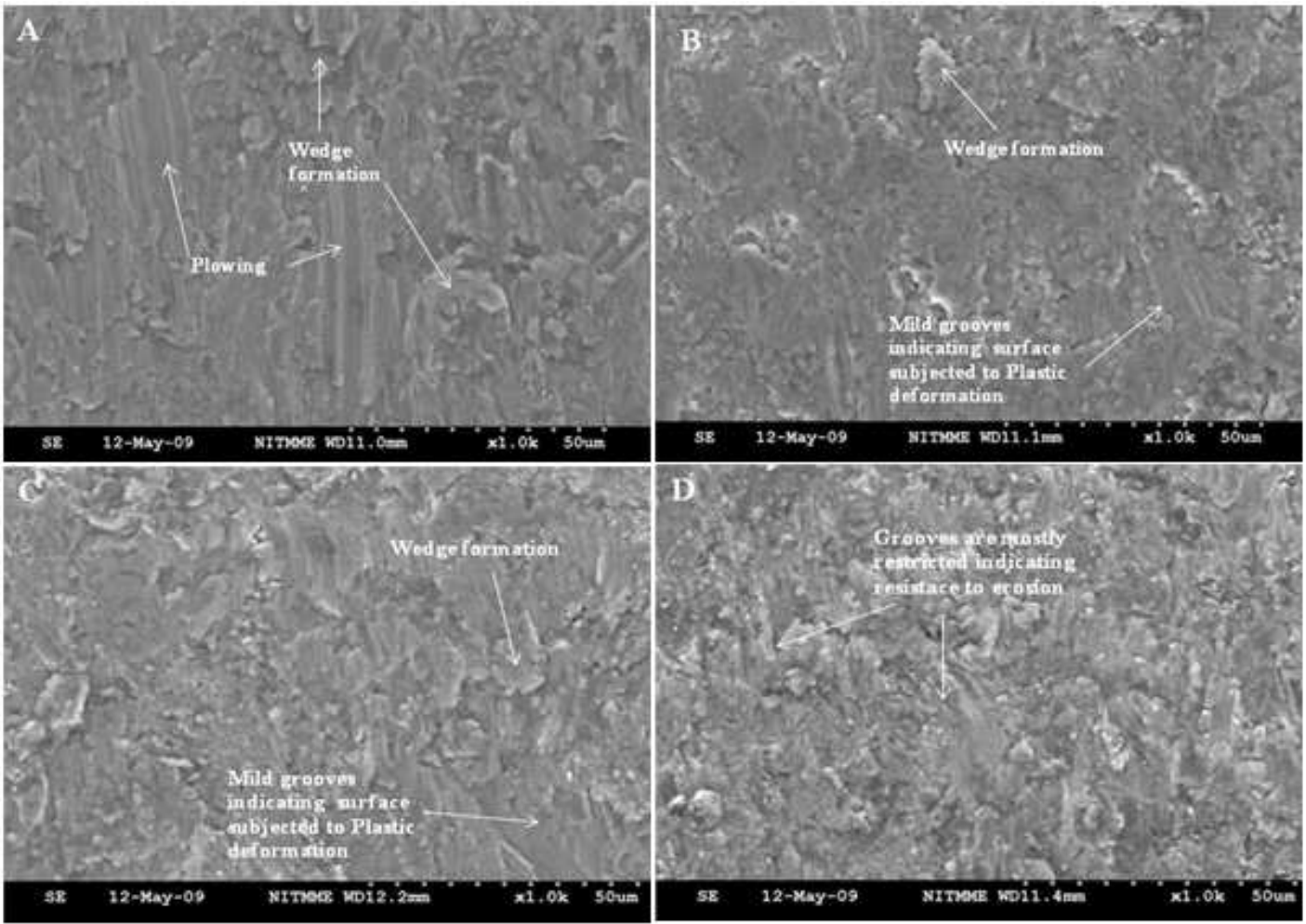

Figure 5: SEM Micrograph of AA 6063/TiC with Solutionized-Aged Condition after Erosive Wear $A$ ) $\left.\left.C_{0}, B\right) C_{1}, C\right) C_{2}$ and D) $C_{3}$

The aluminum material is deformed plastically on both sides of the plowing grooves without any restriction. Wedge formation in the unreinforced alloy is observed by chisel action of sharp sand particles present in the slurry. With increase in weight fraction of Tic particles in the composites the plowing grooves seems to decrease in size and number. The grooves seem to be restricted by the resistance offered to indentation by Tic particles (Fig. 5d). The presence of silica 
sand particles in water was responsible for erosion-abrasion wear of surface of the composites. The erosion is mainly caused by plowing, plastic deformation, wedge formation and voids. The plowing action and plastic deformation are predominant in unreinforced alloy and lesser reinforced composite $\mathrm{C}_{1}$. Whereas, voids caused due to removal of hard faced Tic particles are observed due to the impact of sharp sand particles in composite $\mathrm{C}_{2}$ and $\mathrm{C}_{3}$.

\section{CONCLUSIONS}

The present investigation has led to the following conclusions: It is possible to produce in situ Tic particles in an AA 6063 alloy $-\mathrm{K}_{2} \mathrm{TiF}_{6} / \mathrm{C}$ system through a simple and cost effective in melt reaction synthesis. The SEM and micro hardness testing results indicated the presence of Tic particles which have been proved by XRD analysis and hence, the feasibility of the composite. Thesolution zing -aging of the composite shows good improvement in the hardness of the composite as compared to solution zing heat treatment alone. Erosive wear rate decreased with the presence and increase on Tic particles in the composites. In erosive wear tests, composites with solution zed-aged condition emerged to have better wear resistance than compositeswith solution zed and as-cast conditions. In the case of erosive wear, the predominant mechanism of wear was plowing and wedge formation for unreinforced alloy, whereas, voids creation in composites $\mathrm{C}_{2}$ and $\mathrm{C}_{3}$ is the major cause of material loss.

\section{ACKNOWLEDGEMENTS}

The authors wish to express their gratitude for the provision of excellent experimental facilities, used for this work, established under Technical Education Quality Improvement Programme (TEQIP)under a World Bank funded MHRD Scheme by Government of IndianiteDepartment of Metallurgical and Materials Engineering, National Institute of Technology, Tiruchirappalli.

\section{REFERENCES}

1. Amir Bahri, NoamenGuermazi, Khaled Elleuch, Mustafa Ürgen. On the erosion wear of 304 L stainless steel caused by olive seed particles impact: Modeling and experiments. Tribological International, Volume 102, October 2016, Pages 608-619.

2. E. Vuorinen, N. Ojala, V. Heino, C. Rau, C. Gahm. Erosive and abrasive wear performance of carbide free biotitic steels comparison of field and laboratory experiments. Tribological International, Volume 98, June 2016, Pages 108-115

3. H. Chen, J.Xing, W.Li, Application Handbook of Wear Resistant Materials, China MachinePress, Beijing, 2006.

4. Y.Qu, J.Xing, X.Zhi, J.Peng, H.Fu, Effectofceriumontheas-castmicro- structure of hyper eutectic high chromiumcastiron, Mater.Lett. 62(2008) 3024-3027.

5. C.Scandian, C.Boher, J.D.B.deMello, F.Rézaï-Aria, Effect of molybdenum and chromium contentsin slidingwearofhighchromiumwhitecastiron: the relationship betweenmicrostructureandwear, Wear267 (2009)401-408.

6. X. Zhi,J.Xing,Y.Gao,H.Fu,J.Peng,B.Xiao, Effect of heat treat menton microstructure and mechanica propertiesofaTibearinghypereutectichigh chromium whitecastiron,Mater.Sci.Eng.:A487(2008)171-179.

7. Q. Zhou, AntiwearChromiumSystemCastIron, Xi'anJiaotongUniversityPress, Xi'an 1986, pp.18-19.

8. E. Zumelzu, I.Goyos, C.Cabezas, O.Opitz, A.Parada, Wearand corrosion behavior of high-chromium (14-30\% Cr)castironalloys,J.Mater.Process. Technol.128(2002)250-255.

9. W.Lu, L.Li, L.Huang, CastAlloyandItsSmelting, ChinaMachinePress, Beijing, 2002.

10. H.Baker, H.Okamoto, Alloyphasediagrams, ASMInternational, ASMH and book. 3, 1992, pp.501. 
11. Z.Lv, H.Fu, J.Xing, Z.Huang, S.Ma, Y.Hu, Influence of boroncontentsonoxidation behaviorandthediffusionmechanismofFe-B basedalloysat 1073Kinair, Corros.Sci.108 (2016)185-193.

12. S.Ma, J.Xing, H.Fu, Y.He, Y.Bai, Y.Li, Y.Bai, Interface characteristics and corrosion behavior of oriented bulk Fe2 Balloyinliquidzinc, Corros.Sci.78 (2014)71-80.

13. Y.Wang,J.Xing,S.Ma,G.Liu,Y.He,D.Yang,Y.Bai,EffectofFe2Borientation on erosion-corrosion behaviorofFe-3.5 wt\%Bsteelin flowing zinc,Corros. Sci. 98(2015)240-248.

14. S. Ma, J.Xing, Y.He, H.Fu, Y.Li, G.Liu, Effect of orientation and lamellar spacing of Fe2 Boninter faces and corrosion behavior of Fe-Balloyinhotdipgalvanization, ActaMater.115 (2016)392-402.

15. Y.Wang,J.Xing,S.Ma,B.Zheng,H.Fu,G.Liu, Interfacialmor phologiesand erosion-corrosion behaviorofdirectionalFe3.5wt\%Bsteelin flowing liquid Zn containing0.30wt\%Al,Corros.Sci.112(2016)25-35.

16. Y.Wang,J.Xing,S.Ma,B.Zheng,G.Liu,D.Yang,Y.Bai,Interfacecharacterization and erosion-corrosion behaviorofdirectionalFe3.5wt\%Bsteelin flowing liquidzincatvarioustemperatures, Corros.Sci.104(2016)260-268.

17. L. Musen, F.Shaoli, X.Wandong, Z.R.Y.Ruihuang, Valence electronstructureof Fe_2B phaseanditseigen-brittleness, Acta Metal.Sin.31(1995)201-208.

18. O. Ozdemir,M.Usta,C.Bindal,A.H.Ucisik,Hardironboride(Fe2B)on99.97 wt\% pureiron,Vacuum80(2006)1391-1395.

19. S. Ma,J.Xing,G.Liu,D.Yi,H.Fu,J.Zhang,Y.Li, Effect of chromium concentrationon microstructure and propertiesofFe-3.5 Balloy,Mater.Sci.Eng.: A 527(2010)6800-6808.

20. X. Chen, Y.Li, H.Zhang, Microstructure and mechanical propertiesofhigh boron white castiron withabout 4wt\%chromium, J.Mater.Sci.46 (2011) 957-963.

21. C. Zhou,J.Xing, B.Xiao, J.Feng, X.Xie, Y.Chen, First principles study on the structural properties and electronic structure of X2B(X1/4Cr,Mn,Fe, Co, Ni, Mo and)compounds, Comput.Mater.Sci.44(2009)1056-1064.

22. B. Xiao,J.Feng,C.Zhou,J.Xing,X.Xie,Y.Cheng,R.Zhou,Theelasticity,bond hardness and thermo dynamic cproperties of $X 2 B\left(X^{1 / 4 C r}, \mathrm{Mn}, \mathrm{Fe}, \mathrm{Co}, \mathrm{Ni}, \mathrm{Mo}, \mathrm{W}\right)$ investigated by DFTtheory, Phys.B:Condens.Matter405(2010) 1274-1278.

23. Y.Jian, Z.Huang, J.Xing, B.Wang, Effectsofchromiumadditiononfracture toughness andhardnessoforientedbulkFe2Bcrystals, Mater.Charact.110 (2015)138-144. 
